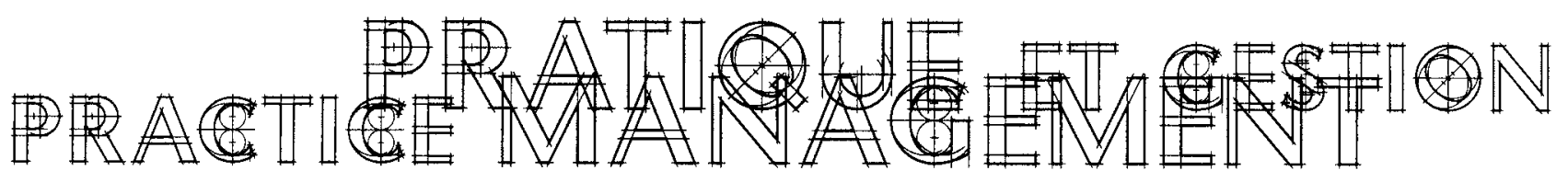

\title{
What It Takes To Succeed
}

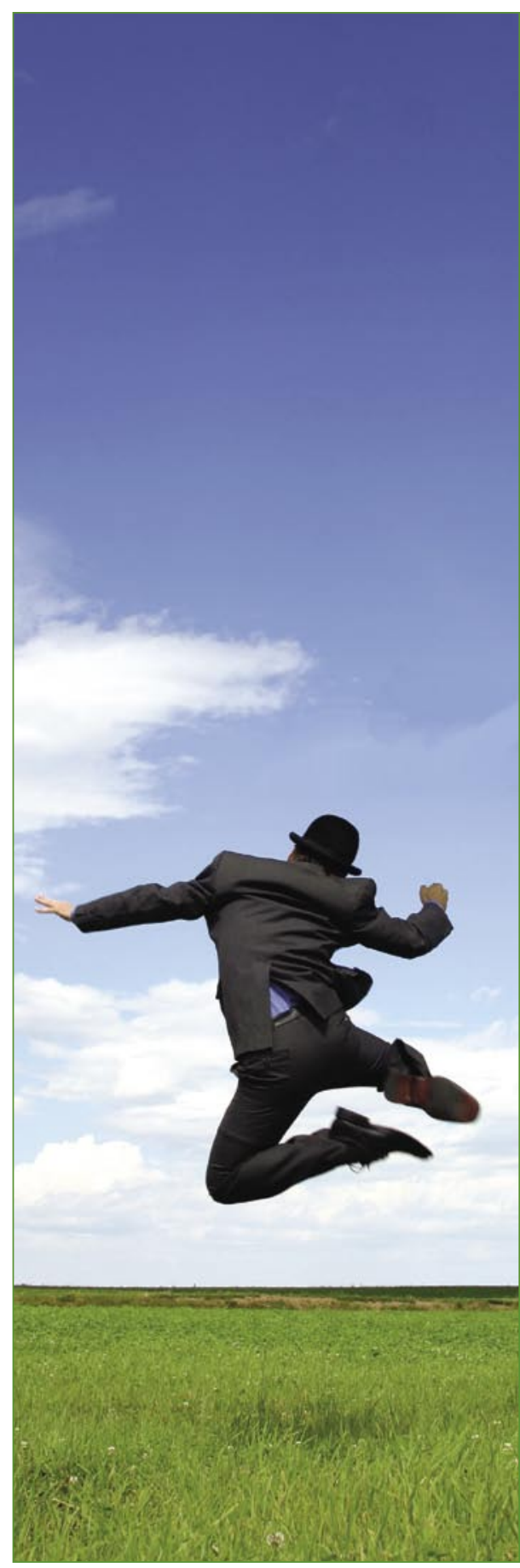

A s optometrists, we survived the rigors of our training, found our place as entrepreneurs in private practice and enjoy very comfortable lifestyles. From this we may assume that we are successful. However, is this the only measure of success? Is this your personal definition of success?

The definition of success that I like comes from H. G. Wells, who said that the measure of success is the ratio between what we might have become and what we have become. Success is determined by how close you come to your true potential. Have you taken the time to think about what your true potential might be?

A good starting point is to define your purpose in life. What is the meaning of life for you? What are you passionate about? What would you gladly do even if you had to do it for free? You should try and be concise and focus on as few as possible. Concentrate on a purpose for each of your professional and personal lives.

Your life-meaning should answer the question: where would you go, if you could go anywhere in this life?; How would you live?; What would it look like? Try not to think in terms of gaining riches, fame, power or processions - these don't last and are not full-filling in the long run. Your purpose is not tied to these tangible destinations, it is the journey itself.

Take into consideration your personal strengths, what are your natural talents? It is much easier to swim with the current, so identify your greatest talents and your strongest character traits, then use them to your advantage and propel yourself further, faster.

To achieve any level of success you have to maintain a positive attitude. You need to believe in yourself, believe that you can fulfill your greatest potential. It won't be easy, for there will

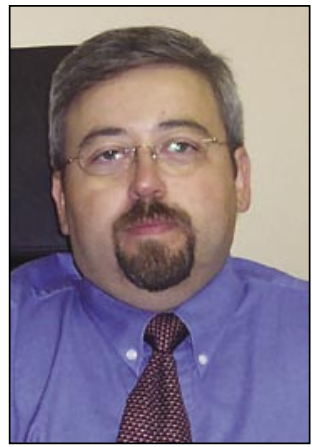




\section{PRACTICE MANAGEMENT PRATIQUE ET GESTION}

be obstacles and adversity. There will be risks, and you may have to overcome some fears, the biggest of which is the fear of failing. All very successful people have had to deal with failure. They learned from their mistakes, put it behind them and went on to greater things. Accept it as one of the prices of admission to fulfilling your purpose. Remember that losers call it failing but winners call it learning.

To be successful you will need the help of others; you can't do it alone. Enlist your family and peers to help you fulfill your potential. Surround yourself with people who are honest, helpful and positive about the goals you have. Share these goals with them, create alignment that pushes you forward. It is a bit of a cliché but the people that you surround yourself with will ultimately determine the level of your success.

Even though you live to fulfill your purpose in life, you need to set goals along the way. These act as landmarks to guide you and let you look back to see how far you have come. Don't confuse the act of attaining these goals with attaining success, this only comes from living your life to its greatest potential as defined by your purpose.

Your goals will continue to change over time. You will need these realigned when new opportunities arise or

\section{Is that an Expense or an Investment?}

Are we benchmarking the right things? G. R. Leinweber B.Sc., O.D.

Optometrists love reducing issues to numbers. They want to know:

- what $\%$ of gross income to pay their staff

- what $\%$ of gross income to pay for rent, overhead
- what the ideal ratio of new us previous patients is for a practice -... plus 20 more that "experts" tell us we should measure

Yet, in my experience consulting with Optometrists from coast to coast, very few track the-key or" vital statistics" of their practice. And even fewer track them monthly, nor do they share themwith their team, and as a result, few know the facts they need to lead their team forward;

- what their gross and net profits were last month, and YTD versus the previous year,

- what their GMROI (Gross Margin Return of Investment) was for stock or equipment,

- even fewer know how satisfied patients were after being examined or dispensed,

- and almost none measure and track how satisfied their staff were.

I want to focus in this article on what the difference is between an expense and an investment, plus explore why we need to focus on investing. The most vital commodity any successful practice has is TRUST. Trust cannot be bought, bartered, or sold; it must be earned. Optometry is a profession which potentially allows doctors and their team members to increase levels of trust with patients, developing and earning loyalty from patients. So, how do you measure trust? I have found you must measure it indirectly, simply ask patients in an exit interview if they would refer friends or family to your office. If they would, you have earned their trust. If they would not - you have some more work to do.

So what are the basics of the eye care business? People have vision problems which they want solved - and they prefer the experience to be pleasant, maybe even fun. Three models of providing solutions have developed. At the risk of oversimplification, they are; the full service model (e.g. Optometrists who dispense glasses, CL, etc which they purchase from various suppliers), the segregated model (where the examination, CL dispensing, and glass dispensing are provided in separate offices), and the vertically integrated model (where the manufacturer owns or controls the dispensing and examinations which are offered in side by side locations). In the past 


\section{PRACTICE MANAGEMENT PRATIQUE ET GESTION}

when obstacles present themselves. Your life's purpose doesn't change, but your goals shift to deal with the new realities.

A good analogy that demonstrates most of these points is a sailing adventure. Before you leave the dock you should have your final destination in mind and mapped out. You will need a skillful crew that you can rely on and support your journey. Because you can rarely sail directly to your destination, you need to set certain waypoints along the way, your goals. Sometimes it may even seem that the path you are on is moving you away from your destination. As winds and currents change you may need to alter your course, and with the help of your crew you can get yourself back on track, onto your destination.

As you travel along and meet your goals you need to celebrate with your crew. This is especially true when you finally get to your destination and when you get there you'll realize that purpose of the trip wasn't the destination itself, it was the journey with your friends that was the real purpose.

Define your personal and practice success in terms of the potential that both have and work daily to grow to that potential, then success will truly be yours.

decade, the vertically integrated model has captured significant market share from the segregated model. Yet if you survey the public, the majority doesn't care about the delivery model; they want quality, value, and convenience for both diagnostic and treatment options at an office where they can trust the doctor and the staff.

The public has more sophisticated consumers than ever. Yet, in North America, they have tremendous unmet wants and needs in their eye care. Three examples we should ponder:

(1) far fewer Canadians (7\%) wear contact lenses compared to the US population (13\%),

2 far fewer North American patients have multiple pairs of glasses than the Europeans,

3 sunglass sales in professional offices were so poor, new chains such as Sunglass Hut have sprung up to fulfil the public's wants and needs.

The concept of having suppliers and Optometrists working together on a message or program is not new, but CAO (through EHCC) created a structure that is indeed different and effective. Yet, unless OD's and our suppliers see growth in their businesses - in both the short and the long term - such public relations programs will not be sustainable. While an external marketing program is good to have, your investment in an internal marketing program that you measure is essential. I urge every OD in Canada to make a strong investment in an internal marketing program, and that for external marketing, you support CAO and your provincial associations who may piggyback on "Your Eyes Deserve an Optometrist"

How can you have an effective internal marketing plan? Involve the suppliers who are key supporters of EHCC with your internal marketing programs, have their reps help train your team about product knowledge. When you sit down and do your annual budget, (I strongly recommend you do one, just a simple 7line budget will do -email me and I'll show you how) consider what investments you will make in your profession, in your office, and in your future. Learn to look at costs to see not all are expenses, but some are indeed investments which can and should:

- increase your gross and net profits,

- increase your ROI (return on investment),
- increase patient satisfaction/loyalty, and

- have a happy productive support team in your office.

You can accomplish all this by working with and partnering with suppliers in a quest for mutually beneficial, healthy growth. 